\title{
Book Selection: A National Plan for Small Academic Libraries
}

\begin{abstract}
A Although building the collections is one of the most important tasks of librarians, comparatively little attention has been given to this aspect of professional work. The system in current use has been practiced for many years with little systematic scrutiny and with little discussion of possible alternatives. This applies to nearly all academic libraries, but the present article will address itself mainly to problems of the smaller institutions rather than those of the major university libraries.
\end{abstract}

How are books selected for academic libraries? While patterns vary from one extreme to the other, in most institutions both librarians and faculty members participate in building collections. Many problems arise, for while faculty members play a major role in selection, librarians know very well that faculty selection is often of questionable merit. Among the most conspicuous deficiencies are: (1) many faculty members are already overburdened with other duties; (2) some of them lack acquaintance with the world of books; (3) some do not care (the textbook is enough); (4) a few suffer from a constitutional inclination toward laziness; (5) some select books in their own narrow field of specialization without regard for the needs of students; and (6) some believe that only they are capable of selecting. While this list could be extended, these are some of the major shortcomings of

Mr. Massman is director of libraries and Mr. Olson is head of public services at the University of South Dakota. reliance on faculty selection. As Danton has pointed out, the faculty member who fails to find a particular item in the library blames not himself or another faculty member for the deficiency, but the library for failing to procure the wanted title. ${ }^{1}$

How about librarians? Certainly many of the problems which apply to faculty selection also apply to librarians -lack of time, inadequate acquaintance with books, and laziness. Librarians, however, usually maintain that they are more likely to consider the needs of students, and that they are more concerned about building a balanced collection.

Given an ideal balance between selection by faculty members and librarians, one might expect to develop a reasonably good collection. However, because of the complexities of assembling a complementary library staff and faculty and of maintaining completely harmonious relationships between the two groups, this hope is a virtual impossibility.

Under present conditions the quality of selection in most academic libraries probably leaves much to be desired, but this is not entirely the fault of either the faculty members or the librarians, or even the two in combination. Why? Part of the defect results from the manner in which books get into reviewing journals. This itself has received comparatively little detailed study. The Bowker Annual lists the total number of titles examined in a number of general reviewing journals, but of course 
makes no effort to assess the quality of reviewing nor the duplication of coverage (i.e., whether a particular title received notice in more than one journal). ${ }^{2}$ To a considerable extent the editors of the reviewing journal depend upon the publisher to send new works for examination. The editor must then determine whether a particular book is suitable for review in his journal and give the book to a reader who may or may not return his evaluation within the specified period of time. The latter situation is an especially vexing problem regarding reviews in scholarly journals. The specialist to whom the book is sent for examination is often busy with more pressing tasks, and may take six months, a year, or more to read the book, write his commentary, and submit it for publication-if he gets it done at all.

That the current system is haphazard can be illustrated to some extent on the basis of difficulties encountered by CHOICE. This journal farms out reviewing duties to a large number of librarians and faculty members, and the editor himself does not know what will be in each successive issue until virtually the last minute. ${ }^{3}$ What appears in each number depends upon copy submitted by reviewers. If the reviewer is dilatory, it may take him three months or six months to send in his report. This is not to blame the editor of CHOICE, for he is at the mercy of his geographically dispersed staff of voluntary contributors. To manage such a task must take an unusual measure of patience and dedication. Nevertheless, even when it works well, the system leaves much to be desired.

Thus, before the librarian has a chance to see the review and before a book receives a printed notice, the book must ordinarily be sent out by the publisher, meet the editor's standards, and await evaluation by the critic selected to review the work. The book re- view editor himself may reject many items, not because he necessarily questions their merit but because the title does not fall into the subject categories or the type of literature (e.g., scholarly or popular) deemed appropriate for that journal. Because of the way the system works a large mass of literature, then, never comes to the librarian's attention unless he consults a large number of reviewing journals.

How unpredictable the vagaries of reviewing journals are can be illustrated by taking five specific examples. Each of the five titles to be discussed was checked against the Book Review Digest and the Book Review Index to locate reviews. ${ }^{4}$ The first two examples are significant titles partly because they are of interest to minority groups. The other three are of value because they deal with certain aspects of higher education. All five books belong in every academic library in the United States.

Which journals reviewed these five books? The first example, published in 1967, was Donald C. Dickinson's BioBibliography of Langston Hughes. Because it contains extensive information about one of America's great black poets it is a basic study which is essential for anyone who is interested in the broad sweep of American literature, yet it received a notice only in Nation and Library Journal. The second work, Vine Deloria's Custer Died for Your Sins: An Indian Manifesto, was published in 1969 and was reviewed in America, Best Sellers, Library Journal, New York Times Book Review, Newsweek, Saturday Review, and Time. ${ }^{5}$

The other three books chosen as examples deal with issues that are of primary concern to librarians and faculty members. The first, T. Caplow and R. J. McGee's The Academic Marketplace, discusses hiring practices of institutions of higher learning. It was published in 1958 and was reviewed in Library Journal and the Chicago Sunday Tribune. 
The second book, Mark Ingraham's The Outer Fringe: Faculty Benefits Other than Annuities and Insurance, was published in 1965 and was reviewed in $\mathrm{Ca}$ nadian Forum, Journal of Higher Education, Library Quarterly, Science, and Teachers College Record. In this case, as is true for the next item, the subtitle gives a good indication of the content. Mark Ingraham's The Mirror of Brass: The Compensation and Working Conditions of College and University Administrators was reviewed by CHOICE and by $C R L$.

As already suggested these five items should be available in all college and university libraries, but no single reviewing journal covered all of them. Library Journal noted The Academic Marketplace but not The Outer Fringe or The Mirror of Brass. Of the three books just mentioned, CHOICE reviewed only the latter. (CHOICE was, of course, not yet in existence when The Academic Marketplace was published.) Similarly, the Journal of Higher Education and Teachers College Record reviewed The Outer Fringe but not The Academic Marketplace or The Mirror of Brass. Oddly enough, none of the five journals which reviewed The Outer Fringe reviewed The Mirror of Brass or The Academic Marketplace. Is there any rationale for this, or does it reflect the hazard of chance by which books are reviewed by one or another journal?

Take a half hour to examine the Book Review Digest or the Book Review Index and see how many books which are of value to academic libraries are reviewed only by scholarly journals or only by the general journals. Furthermore, see how many books which are of value to academic libraries are cited with only one review in Book Review Index. (The Book Review Digest normally does not cite titles which received only one review.) If one depends upon reviewing journals as a major source of information for building collections, such an examination may be both enlightening and disturbing to the person concerned about quality selection.

A recent article in CRL discussed the reviews of books in seventy-one scholarly journals. ${ }^{7}$ Of the 3,195 titles examined for that article, only about 15 percent received a notice in more than one of the seventy-one periodicals. Thus, 85 percent were reviewed by only one journal. This meager duplication is rather surprising. One would expect far more overlapping within the journals for history or for English, for example, or for any other discipline. Because there is not, however, it is necessary to examine at least several journals for each discipline, and the total number could easily come to seventy-five or more for all the various courses offered in the undergraduate curriculum in most colleges and universities. Even such extensive examinations of reviewing journals still would not assure the appropriate range of coverage-to say nothing about the quality of reviewing.

In discussing the advantages and shortcomings of blanket order plans, comparatively little attention has been paid to the deficiencies of the current system of reviewing new books. A blanket order plan that is handled by a good dealer is probably capable of giving the library more effective coverage of current books than a system of relying upon reviews.

The study of the feasibility of centralized processing in Colorado academic libraries, for example, found that the approval dealer supplied 40.4 percent of the titles reviewed in CHOICE during the first year and 45.1 percent for the second year. ${ }^{8}$ The writers suggested that the approval plan needed to improve its coverage because it provided such a small percentage of the CHOICE titles.

When the list of 3,195 books examined for the CRL article mentioned previously and which received favorable 
reviews in the journals was compared with $C H O I C E$, duplication approached only 30 percent. Thus the approval dealer mentioned in the preceding paragraph achieved a higher overlap with CHOICE than CHOICE did with the scholarly journals. When the 3,195 titles were compared with the Book Review Digest, duplication approached 50 percent. ${ }^{9}$

Then there are also the general reviewing journals such as Saturday Review, the New York Times Book Review, etc. In many instances, as an examination of the Book Review Index will demonstrate, a book which is significant to academic libraries may be reviewed by only a scholarly journal or by only general journals. Thus to insure effective selection, the library must devise a scheme which will assure adequate selection based on thorough and ragular examination of the general reviewing organs as well as a large number of specialized journals which carry reviews.

Under the present system it is extremely difficult to insure the building of first-rate collections. It is, therefore, unfair to place undue blame on librarians for deficiencies in building collections, for the present method is virtually impossible to cope with. The librarian may be doing an excellent job of selecting from those journals which he finds time to read; it is impossible to read them all. To then use the standard procedure of evaluating the collection by checking it against recommended book lists and blaming the librarian if the collection appears to be deficient is affixing blame on a potentially innocent party. Much of the blame might more deservedly rest with the inadequate reviewing system.

A new approach must be found. Although many librarians will object to any suggestion of centralized selection, they should be aware of the fact that publishers and journal editors do a great deal of selecting simply by deciding which works will or will not be reviewed. Over this the librarian has no control.

For a moment, it may be worth examining a few of the major objections to centralized selection. Presumably, the librarian knows his clientele, buys with individual readers in mind, understands their special needs, and is aware of how his people use books. But is there really any documented evidence that librarians (individually or en masse) know their communities as well as they think they do? What constitutes knowing the patrons? Does the opinion of one vociferous faculty member speak for the faculty? To turn to a slightly different area, librarians have strong feelings about whether sets should be classified as sets or whether journals should be classified with books. Is there any substantial evidence that either sets or journals are used more effectively in one way or the other? Is there any "scientific" evidence, in other words, which goes beyond the unsubstantiated assumptions to which we cling so dearly, but which are at opposite points of the issue? Possibly the arguments for local book selection are similar. Possibly the librarian believes he can select more effectively for his patrons than anyone else, but he has no concrete evidence to support his view. Do most librarians select with some shadow of their own image (or the projection of themselves) in mind? Is it possible for the librarian to know what the vast majority of faculty members and students need? The librarian may heed the few whom he knows, but then he should be willing to admit he is doing that and nothing more. Much of the same holds true for selecting for subdivisions of the curriculum. The general content of American history is known; the facts are the same regardless of where American history is taught. One professor may stress the Civil War or immigration, but what if he leaves or if his course is dropped from the 
curriculum? It does happen. Furthermore, if a professor or if the entire faculty stresses a particular aspect of American history, the library still needs the important works dealing with other aspects of that subject.

Carried to its logical extreme, the concept of selection for present clientele would necessitate the reorientation of the collection every fall when the new crop of students and faculty members arrives. And what happens when this librarian with his extraordinary insight into the needs of his clients leaves? Will he then be capable of immediately adjusting his extrasensory wave lengths to his new clients at another institution? The contention that the librarian is selecting for particular individuals sounds convincing. However, if the librarian is indeed buying particular titles with the needs of one person in mind, is he placing undue emphasis on the unique needs of an individual at the expense of the common needs of the group? Library users do have unique needs, but on the undergraduate level they have more in common than they have in isolation. This is what the "standard works which represent the heritage of civilization" in the "Standards for College Libraries" is about. ${ }^{10} \mathrm{~A}$ well-selected collection of books on American history is good anywhere, and not because it happens to serve a particular group of students or faculty members in Alabama, Alaska, South Dakota, or Minnesota.

This paper argues then that the present system of selection by librarians and faculty members does not produce the quality of collections needed. This is true for several reasons which may be summarized briefly. (1) Smaller libraries cannot rely on Publishers' Weekly, American Book Publishing Record, or Library of Congress proofslips for selection; for if they do, they are buying blind. (2) Whether librarians like it or not, under the present system the editors of reviewing journals already en- gage in extensive prejudging (selection by inclusion and by omission) both in determining whether a book will be reviewed and who will review it. (3) In order to insure full coverage of current book production, a large number of current general and scholarly journals must be examined regularly and thoroughly, and few libraries have the staff time necessary to accomplish such a large task.

A practical alternative might be centralized selection on a national basis. The system might work something like this. The Association of College and Research Libraries or ALA's Library Resources and Technical Services Division would manage the program and would hire subject specialists (twenty individuals with backgrounds in different disciplines should be able to insure good coverage) who would examine all new books currently being published and who would decide which books were appropriate for the undergraduate level. Depending upon the volume of book production, the twenty specialists would select a total of about 5,000 books per year. The total number would fluctuate with the quality and quantity of publication each year, but 5,000 titles would be a reasonable number for purposes of discussion. This is admittedly a round figure, based to some extent on research but also based to some extent on conjecture. A more precise figure could be arrived at as a result of more extensive study. Libraries could buy the package, but they could not make any stipulations about what they would accept or reject. They would take all or nothing. No exceptions of any kind would be permitted.

Such a system could have tremendous side benefits. Why no exceptions? By insisting upon a total acceptance of the package, the program could achieve considerable economies. Attempting to tailor selection to the separate libraries would destroy the program before it 
had a chance to work, but the package sold to 200 libraries could have tremendous economies of scale. One cataloger using Library of Congress copy could supervise the cataloging of 5,000 volumes (actually 5,000 for 200 libraries equals $1,000,000$ books). Complete card sets could be produced with call numbers in place. The circulation card and book pocket could also be included.

The secret of success would be in the processing of 200 copies of the same book at the same time. Producing 200 sets of cards for one title would permit the use of the best equipment and obviously would be far faster and more economical than doing it separately in 200 libraries.

One of the major problems in centralized processing is the matter of exceptions. If the processing center allows exceptions, errors are more likely to occur and every member helps to pay for the specialized treatment because exceptions take time and therefore cost money. (For a good discussion of the problems of centralized processing see the Fall 1966 issue of Library Resources d Technical Services.) Furthermore, the simple matters such as spine labeling and producing circulation cards can sometimes be done more economically in the local library than in the central system. However, if this is done en masse, it can be done more economically.

It is only when the routine can be done en masse and without a long list of exceptions for each participant that the routines can be done more economically in the central system, for only then does automation provide significant advantages. A computer, for example, has an advantage over routine manual operations in libraries primarily when the same task must be performed a number of times. If a particular task needs to be done only one, two, or three times, it is likely that the computer will be an expensive luxury.
It is interesting to note that in her study of centralized processing centers Vann reported that the buyer-librarian was most likely to be dissatisfied with details of processing rather than with cataloging and classification itself-as if the location of the book pocket were the essence of cataloging and usability. ${ }^{11}$ Uniform processing for all libraries could ensure a quality product, and it would not cause significant problems for cooperating libraries. It would, of course, mean that all participating libraries would have to accept the same classification scheme, but this should create no insurmountable difficulties either.

How much would such a plan of centralized selection-acquisitions-processing cost? Broken down by category, it might run something like this:

Selection: twenty complementary subject specialists at an average of $\$ 15,000$ per annum

$\$ 300,000$

Cataloging: one professional (should be on the same level as the subject specialist and his salary could be averaged with that group) $\$ 15,000$

Catalog card sets, including labor and machine costs: $\$ .10$ per set for 200 copies of 5,000 titles or a total of $1,000,000$ sets

$\$ 100,000$

Processing including all labor: $\$ .25$ per book for spine labeling, circulation cards, book pockets, matching cards with books, etc. $\$ 250,000$ Administration

Warehouse and equipment: $\$ 3,000,000$ amortized over twenty years

$$
\text { TOTAL } \frac{\$ 150,000}{\$ 850,000}
$$

Assuming the average price of books to be $\$ 10.00$ per title and an average discount of 10 percent per title when purchasing 200 copies of each of the 5,000 
titles, the centralized acquisitions system would be able to manage all selection, cataloging, and processing for less than the average $\$ 1.00$ per copy discount (200 copies of 5,000 titles equals $1,000,000$ books at $\$ 10.00$ per book equals $\$ 10,000,000$ and a 10 percent discount equals $\$ 1,000,000$ discount). ${ }^{12}$ The total cost of $1,000,000$ books, then, would be $\$ 9,000,000$, and the cost of processing would be $\$ 850,000$. On a per copy basis this would mean $\$ 9.00$ per copy and $\$ .85$ for processing.

Thus the discount would more than cover selection and all processing costs. The library would be able to build a quality collection with the books coming to the library ready for the shelves and the cards ready for the catalog at less than the list price of the book. This in spite of the fact that the cost estimates above are computed at a rate which is probably higher than they would be in an actual operation.

For example, by using Library of Congress copy and offset printing, one worker can easily run 120 cards per minute. Using a more conservative average production of only sixty cards per minute would mean that one person could produce 3,600 cards per hour (600 sets with an average of six cards per set). At $\$ .10$ per set this would mean an income of $\$ 60.00$ per hour. This would allow a generous $\$ .01$ for card stock $(\$ 36.00$ for 3,600 cards), $\$ 8.00$ per hour for labor, $\$ 8.00$ per hour for machine rental, and $\$ 8.00$ per hour for other expenses. Most businesses would be eager to achieve that kind of return on their investment. Another illustration, the $\$ 3,000,000$ for the warehouse and equipment, is probably high. At a cost of $\$ 50.00$ per square foot, $\$ 1,000,000$ would provide 20,000 square feet. Another $\$ 1,000,000$ for equipment would be quite generous. Thus $\$ 1,000,000$ would be left for contingencies.

A larger number of subscribers would further reduce the per title processing costs, but even with only 200 subscribers, the smaller libraries could nearly disband their acquisitions, cataloging, and processing centers and invest that money in books. Acquisitions and processing costs in nine Colorado academic libraries averaged $\$ 4.09$ per book without considering institutional overhead. The comparable Colorado Cooperative Book Processing Center cost was $\$ 3.10$, or $\$ 2.96$ as calculated in the mathematical model. If two copies of each item could be ordered and processed simultaneously, the cost of each item would be reduced to $\$ 2.27$, disregarding institutional overhead..$^{13} \mathrm{~A}$ more recent report gives an average cost of $\$ 3.10$ per book for 1967 and \$2.70 during last year's experimental period. ${ }^{14}$ The system described in this article could perform the same tasks plus the more significant work of selection for $\$ .85$ per book. At a cost of $\$ 49,250(5,000$ titles at $\$ 9.00$ each plus $\$ .85$ each for processing), participating libraries would have greatly increased their purchasing power by practically eliminating the costs of their cataloging and acquisitions departments.

Using the average cost of $\$ 4.09$ for the Colorado academic libraries and without considering institutional overhead, the processing costs for 5,000 titles would be $\$ 20,450$. Since the system described in this article would cost only $\$ 4,250$ ( 5,000 titles at $\$ .85$ each), each library would save $\$ 16,200$ in processing costs. Problems with financial records would also virtually disappear for the libraries because bills would come once a month or once a quarter. Billing by the centralized system would also be simple-the same bill would go to everyone.

Saving $\$ 16,200$ in acquisitions and processing costs for 5,000 titles would be no small matter for most libraries. In addition, the library would be assured of a higher quality of selection. On any given afternoon, a college's entire faculty (including the president) and the library staff could meet in the 
library, unpack the beautiful new shipment of books, and read the books rather than the reviews. And eventually, this basic, quality collection could become the minimum acceptable standard for accreditation. Any academic library which cannot purchase 5,000 books per year should not be called a library.

Naturally each local library would still need to make provision for unique or additional educational programs and for local materials. However, this would be a comparatively small task.

The twenty subject specialists could examine some 30,000 domestic and foreign titles per year. This would be an average of 1,500 per specialist. Using 200 working days per year as a base, this would mean that each specialist would have to look at an average of 7.5 books per day. Assuming a selection of 5,000 titles per year, each specialist would actually approve an average of 250 titles during the course of one year. Since many decisions for inclusion or exclusion would be fairly routine, the specialists should have adequate time to perform their duties.

The major duty of the administrator for the centralized system would be to insure complete coverage. It would be his job to make sure that all books which might be relevant to the undergraduate curriculum would get into the system so the subject specialists would have a chance to review them. This would be the critical factor, getting the books into the system for evaluation. Aside from this, the administrator would be responsible for supervising all accounts with publishers and libraries as well as routine tasks such as shipping and receiving. He would also, of course, deal with complaints from librarians. Once the system was operating effectively (and he would have to have very hard evidence that it was indeed operating effectively), most complaints could be handled in a fairly routine fashion.

If any librarian complained about such matters as the placement of spine labels and call numbers or whether subject entries should be in red rather than in capital letters, the chief administrator for the selection-acquisitions-processing center would write to the complaining librarian's president (with a copy to the librarian) recommending that the institution summarily fire the librarian.

Why not?

\section{REFERENCES}

1. J. Periam Danton, Book Selection and Collections: A Comparison of German and American University Libraries (New York: Cōlumbia University Press, 1963), p.71.

2. Bowker Annual of Library and Book Trade Information (New York: R. R. Bowker, $1970)$, p.54.

3. Lawrence E. Leonard, Joan M. Maier, and Richard M. Dougherty, Centralized Book Processing: A Feasibility Study Based on Colorado Academic Libraries (Metuchen, (N.J.: Scarecrow Press, 1969), p.171-72.

4. The Book Review Digest has a number of criteria for citing reviews which are explained in its "Statement of Policy" in the annual cumulations, but these need not be discussed here.
5. Although the Book Review Digest had not cited it by June of 1970, CHOICE did carry a review in March 1970. All the other reviews had appeared in October or November of 1969 .

6. Possibly reviews of these works appeared in additional journals without being cited by Book Review Digest or Book Review Index, but no attempt was made to do a thorough search of a large number of journals to locate additional reviews.

7. Virgil F. Massman and Kelly Patterson, “A Minimum Budget for Current Acquisitions," CRL 31:83-88 (March 1970).

8. Leonard, Centralized Book Processing, p.171.

9. The percentages should not be used as ab- 
solute figures since comparisons were drawn for only a small sample. The point to be made is that a substantial percentage of the new books is reviewed by only one journal.

10. "Standards for College Libraries," CRL 20: 276 (July 1959).

11. Sarah K. Vann, "Southeastern Pennsylvania Processing Center Feasibility Study: A
Summary," Library Resources \& Technical Services 10:472 (Fall 1966).

12. For $1969^{\circ}$ an average price of $\$ 9.37$ for American books was reported by Publishers' Weekly (9 Feb. 1970), p.49.

13. Leonard, Centralized Book Processing, p.244.

14. Mountain-Plains Library Quarterly 15:28 (Summer 1970). 